\title{
Applying cognitive task analysis methodology in educational research
}

\author{
Yuliya Kartoshkina ${ }^{1}$, Cheryl Hunter ${ }^{2}$ \\ (Department of Educational Foundations and Research, University of North Dakota, USA)
}

\begin{abstract}
Effective teaching is a valuable skill that is hard to learn and understand by just simply observing someone teach. One of the ways to gain better insight into how this skill is being developed is to explore teachers' cognitive processes. Cognitive Task Analysis (CTA) methodology developed to study the cognition of experts performing challenging tasks can be a useful tool to gain this insight. This paper will review the underlying theoretical assumptions of this methodology and suggest how one could apply CTA to educational research.
\end{abstract}

Keywords: Research methodology, qualitative research, cognitive constructivism, cognitive task analysis

\section{INTRODUCTION}

Effective teaching is a valuable skill that is hard to learn and understand by just simply observing someone teach. One of the ways to gain better insight of how this skill is being developed is to learn about teachers' cognitive processes. However, not all teachers are as skilled as others; therefore, observing a recognized expert in teaching would be more useful than observing a novice or substandard teacher. Cognitive Task Analysis (CTA) can offer researchers a set of valuable tools to elicit knowledge from expert teachers. This methodology was developed to study cognition of experts performing challenging tasks and develop trainings based on the knowledge gained from these experts to train novices (Crandall, Klein, \& Hoffman, 2006). CTA is based on the assumption that an expert teacher has more to offer, and therefore should be closely studied to gain greater insights into the skills being demonstrated.

Over the last decade, there have been many CTA studies conducted and "an unusually broad population of individuals have become interested in conducting them" (Crandal et al., 2006, p.2). Military commanders, computer system analysts, market researchers, healthcare providers, trainers and instructional designers, and people in many other fields are applying CTA methods. CTA studies have been prominent in the medical field to improve transmission of knowledge of expert medical professionals to novice learners. Many recent studies have been conducted with surgeons in an effort to pass along learned expertise to train graduate students and new practitioners into conducting effective medical procedures (Campbell, J., Tirapelle, L., Yates, K., Clark, R., Inaba, K., Green, D., Plurad, D., Lam, L., Tang, A., Cestero, R., \& Sullivan, M., 2011; Diwadkar, G.B., Hunter, C.A., \& Jelovsek, J. E., 2012; Sullivan, Ortega, Wasserberg, Kaufman, Nyquist, Clark, 2008; Yates, Sullivan, \& Clark, 2012). All these studies show that CTA methods are much more efficient in eliciting knowledge about complex medical procedures, developing training materials, and syllabi than other traditional methods based on simple observation and free-flow recollections. It was indicated that experts usually omit up to seventy percent of necessary information when training novices, but with the information elicited through CTA studies, they can recollect the procedures in much more detail. Also, when training materials and syllabi have been developed based on CTA methods, students showed much better results in practical application of the transmitted knowledge than those who were not trained through them.

By being so effective in eliciting knowledge from experts across many fields, we would like to suggest using this methodology in the field of education. In this paper, we will review the underlying paradigm of this methodology, its theoretical and methodological foundations, and suggest how one could apply CTA to educational research.

\section{Choosing Paradigm}

Before conducting a qualitative research study, it is important to identify which philosophical assumptions (also known as paradigms) will guide a researcher's actions. According to Creswell (2007), the researcher needs to take a stand on what he or she thinks about the nature of reality and how things work in this reality (ontology); explain how and to what extent knowledge can be acquired (epistemology); admit that their inquiry is value driven and recognize his or her own values and biases towards the topic and data gathered (axiology); choose language to report the findings that in qualitative research is usually personal, literary, based on definitions that evolve from the participants' meanings rather than those of the researcher (rhetoric); and choose methods that will align with ontology and epistemology (methodology). Choosing a paradigm helps a researcher to direct their inquiry and assist the audience to interpret research findings. However, it is important 
not to forget that all paradigms accepted in qualitative research are "human constructions," can have errors, and need to be approached from the perspective of persuasiveness and usefulness rather than ultimate proof (Guba \& Lincoln, 1998, p. 202).

Constructivism is one of the existing paradigms in qualitative research that is based on the ontological belief that our reality is constructed socially (social constructivism) and mentally (cognitive constructivism). Social constructivism, based on the work of Vygotsky, has been widely used by qualitative researchers. The ontological belief is that there are multiple realities that people develop through social interactions and cultural context. These realities and constructions are not stable and none of them is more "real" than the other. Epistemology is based on the close interaction between the researcher and the participants and the findings are co-created as the investigation proceeds. Thus, methodologies are chosen to provide opportunities for interactions "between and among" investigator and respondents (Guba \& Lincoln, 1998, p. 207). The aim of inquiry is to understand how participants' meanings about a particular phenomenon have been constructed and to provide new interpretations for their constructions. Thus, the language that is used to report the findings is based on meanings and definitions provided by participants. The researcher also must explore and admit how his or her biases towards research topics and processes have been constructed.

Cognitive constructivism has its roots in the work of Jean Piaget and cognitive psychology (Hruby \& Roegiers, 2011). The ontological belief is that people construct meanings about their social reality and act according to them because of certain cognitive functions and processes. Knowledge is seen as something that is actively constructed by learners based on their existing cognitive structures. Researchers are concerned with the mechanisms of intellectual development and the acquisition of knowledge, rather than social and cultural constructions of meanings. The role of the researcher lies in uncovering those cognitive functions and processes by asking people to describe those processes and reflect on them. This paradigm, however, has not been widely used in qualitative research. It is partly because it emphasizes biological functions that help humans construct their social realities, the lens that has not been traditionally included in ontological discussions of qualitative research. Another explanation is that the recent advancement in tools studying cognition has not been available before.

We would argue that in order to understand such complex phenomenon as teaching, it is necessary to know what is happening in teachers' minds when they seek to transfer certain mental models that help students navigate and co-create various social and cultural realities. There already are various tools developed to study social construction of reality, but it would be valuable to add new tools that will bring insight into what cognitive functions and processes have been contributing to the construction of social and cultural realities, as well as various phenomena in such realities, such as teaching. Therefore, we would like to explore the value of CTA methodology as a means to study cognition of experts. We argue that this methodology can be compatible with the paradigm of cognitive constructivism.

\section{COGNITIVE TASK ANALYSIS}

CTA methodology has been developed to work with experts because their cognition, knowledge, and understanding distinguishes them from their peers. According to Hoffman (1996), an expert is "the distinguished or brilliant journeyman, highly regarded by peers, whose judgments are uncommonly accurate and reliable, whose performance shows consummate skill and economy of effort, and who can deal effectively with certain type of rare or "tough" cases. Also, an expert is one who has special skills or knowledge derived from extensive experiences with subdomains" (p. 86).

There is an extensive amount of research-based literature on cognitive elements that point out how experts differ from novices. According to Chi (2006), experts excel in the following seven areas: 1) generating the best solution in solving problems or in designing a task; 2) detecting and recognizing features that novices usually do not notice; 3) conducting extensive analysis of a problem before taking an action; 4) possessing more accurate self-monitoring skills in terms of their ability to detect errors and status of their own comprehension; 5) choosing more appropriate strategies; 6 ) exhibiting more opportunism in using a variety of information sources and other resources to solve a problem; and 7) being able to retrieve relevant domain knowledge and strategies with minimal cognitive effort, execute skills with greater automaticity, and show more cognitive control necessary in challenging situations. Experts seem to have richer mental models because they understand a wider range of causal connections that govern how things work and can apply them as fast and flexible as it is necessary in a challenging situation (Klein \& Militello, 2004). Thus, experts seem to have highly developed cognitive structures that are important to study, understand, and describe to develop training materials to help others develop similar structures.

\section{Historical Development}

CTA methodology is designed to study cognition because when people are working on complex tasks it is not enough to just observe their actions. Historically, during the era of behavioral psychology that dominated 
the American academic field of psychology during the early 20th century, tasks analysis was used to simply observe highly skilled workers in manufacturing and describe precisely their activities required to perform a variety of jobs and use those descriptions to develop trainings for new employees (Clark \& Estes, 1996). With the development of global markets, increased competition among countries, and technological advances, the nature of tasks became more complicated and simple observation was not enough to study complex analytical and problem solving tasks of experts. Therefore, new insights on how to gather knowledge about the cognitive tasks that guide actions of skilled workers needed to be developed. Cognition started to interest not only people in the workplace but also in a variety of academic and non-academic fields, such as cognitive system engineering, European work analysis, instructional design, computer simulation and human-computer interaction, ethnography of workplaces and cognitive anthropology, cognitive machines and artificial intelligence, and cognitive field research and naturalistic decision making (Crandall et al., 2006). All these communities sought to understand cognitive systems in context by examining how experts and teams of practitioners approach challenging tasks with technological and other types of aids. By sharing their approaches and findings, these communities built the foundation for CTA methods. Those who practice those methods seek to understand what experts know, how they think, how they organize and structure information, and how their thinking influences decision-making and completion of challenging tasks.

\section{Theoretical Foundation}

The theoretical foundation of CTA methodology is based on macrocognition, "the collection of processes and functions that characterize how people think in natural settings" (Crandall et al. 2006, p. 136). It is not designed to conduct experiments in laboratories. People behave very differently when they know they are being observed. The goal of CTA is to understand how people think and make decisions in natural environments.

There are a number of macrocognitive functions and processes that are commonly encountered when conducting field research (Crandall et al., 2006). Macrocognitive functions that people usually engage in when working in challenging environments include making decisions, making sense of situations, anticipating problems, planning and re-planning actions to adapt to a situation, detecting a problem, and coordinating their actions with other people involved in a situation (2006). Most common macrocognitive processes that accompany those functions are the following: maintaining common ground among members of a team; developing mental models that are formed on the basis of previous knowledge, stored in long-term memory, and provide a causal understanding of how situations came about; using mental simulation and story-building to enact series of events and think through them to predict the future; being able to manage uncertainty skillfully; being able to identify opportunities and turn them into action; and being able to use perceptual filters to steer attention (2006). These functions and processes have been studied by various psychologists concentrating on one or several functions or processes. For example, Weick (1995) investigated sense-making in organizations as a response to events that deviate from the conventional understanding of the situation. Klein, Pliske, Crandall, and Woods (2005) compiled an inventory of incidents illustrating problem detection. Hoffman, Trafton, and Roebber (2006) studied how expert weather forecasters reason and create mental models. All these studies illustrate the development of interest in expanding our understanding of cognitive functions that result in certain actions.

\section{Cognitive Decision Method}

Based on the knowledge of these cognitive functions and processes, a wide variety of CTA methods have been developed. Most common are structured interviews with experts; observations of experts' performance, task behavior, and setting; self-reports prepared by experts about their knowledge, behavior, and strategies in dealing with challenging situations; and automated collection of behavioral data handled by computers (Crandall et al., 2006).

One of the most widely used methods in CTA is Critical Decision Method (CDM) - an intensive interview technique developed to elicit knowledge from experts working with complex problems and dealing with specific incidents. According to Hoffman, Crandall, and Shadbolt (1998), this technique seeks to capture knowledge and experience involved in real-world decision-making and problem solving. The main technique in a CDM interview is to go over an incident several times and approach it from different angles to be able to capture a participant's critical cognitive elements. When conducting this interview, the researcher will try to elicit information about such cognitive functions as decision-making, planning, and sense-making within a specific challenging incident. Thus, researchers that choose this method of knowledge elicitation need to have a deep understanding of cognitive demands of both the task and the setting.

According to Crandall et al. (2006), CDM interviews consist of four phases: 1) incident identification, 2) timeline verification, 3) deepening, and 4) "what if" queries. In the first phase, the researcher focuses on identifying an appropriate incident that depends on the nature of the research project and goals for data 
collection. Then, the participant is asked to provide a brief account of this incident, from beginning to end. The initial account and content of the story becomes the foundation for the rest of the interview. In the second phase, the researcher intends to get a clear view of the incident structure as well as identify key events and segments. During this phase, the interviewer works on expanding the initial, brief account of the incident by creating a timeline of events. By verifying this timeline with the participant, more details and corrections might appear. Also, the researcher needs to identify "decision points" when the participant experienced a major shift in understanding of the situation or took some action that affected the events. In the third phase, the researcher attempts to get the story behind the incident by exploring the participant's cognitive processes and functions. This is accomplished by taking the interviewee back to the beginning of the incident and moving through it one segment at a time. There are a number of interview probe questions developed for this phase to help the researcher elicit the cues and information available in the situation, the meaning they held for the participant, and the specific cognitive processes and functions they evoked. The full list of those probes can be found in Crandall et all (2006, p.79). The last phase provides an opportunity for the interviewer to round out his or her insight into the participant's experience skills and knowledge. Using the incident as a starting point, the researcher poses various hypothetical questions about the incident. One way to do this is to invite the participant to speculate on how his or her responses in the event might have differed or how the outcomes might have been altered. Another possibility can be to use props, such as pictures, objects, and storyboards to provide a hypothetical case.

By going through these four steps, researchers have the opportunity to capture main cognitive processes and functions of the participants in a studied context. At the same time, participants will have with the opportunity to share their experiences and gain new insights and realizations on their skills and knowledge.

\section{Trustworthiness}

According to Lincoln and Guba (1985), there are several important elements that need to be considered to insure the trustworthiness of a qualitative study. The researcher is encouraged to think about the following elements: credibility, by requiring a researcher to establish confidence in the truth of the inquiry for participants; transferability, by insuring that the findings can be applicable to a wide range of contexts and respondents; dependability, by determining whether findings can be consistent in the same or similar research projects; and confirmability, by establishing the degree in which the findings are determined by the participants and conditions of the inquiry rather than by the biases, motivations, and interests of the researcher.

To insure the credibility of the CDM method, researchers may use triangulation of data collection methods by conducting interviews together with observations, and collection of artifacts related to an incident; ask peers to debrief the collected data; ask participants to do member checking of the revealed cognitive tasks and processes in the studied context; keep a reflective journal and write down thoughts, observations, new trends in cognitive psychology and CTA methodology along the research process; and use negative case analysis by choosing examples and events that disconfirm the conclusions and seek to explain why.

To insure transferability, researchers need to provide thick description, which in the case of CDM research might include detailed accounts of identifying experts, interview questions and procedures, data analysis process and chosen methods for data representation. Shenton (2004, p.70) also recommends mentioning the number of organizations taking part in the study and where they are based; any restrictions in the type of people who contributed data; the number of participants involved in the fieldwork; the data collection methods that were employed; the number and length of the data collection sessions; and the time period over which the data was collected. To insure dependability, the researcher needs to provide an audit trail with sufficient documentation of all the processes so that other researchers can assess the adequacy of the study; conduct peer debriefing of the findings; and keep a reflexive journal.

To insure confirmability, it is important the researcher provides examples of raw data in the representation of research findings; keeps a reflexive journal to admit his or her predispositions towards the research; asks both peers and participants to look over the findings; and provides data and theory using an audit trail to explain the thought process behind the final conclusions.

\section{Applications In Educational Research}

According to Creswell (2002), there are several important reasons why it is necessary to conduct research in education: to add to the knowledge about educational issues, improve practice, and improve policy debate. CTA methods could be useful for accomplishing all of these goals in various ways.

First, CTA methods can add to the existing pool of knowledge about various educational issues by examining cognitive practices and processes of expert educators. By studying these experts and their cognition, it would be possible to learn about their pool of knowledge and their cognitive functions and processes that they have developed to make their practices so effective. For example, the following is a basic example of a CTA study in math education. Researchers want to understand how to prepare math teachers that will excite 
elementary students about math and develop their math skills that are applicable in everyday life. When conducting such a study, researchers will need to identify expert math teachers based on criteria such as national board certifications, recommendations from national math conferences, recognized leaders in the field, as well as recommendations from both students and other professionals. Likewise, the researcher may want have to access to student performance results. The researcher would conduct interviews with these teachers to learn about how they developed these effective practices as well as what mental processes they engaged in while making decisions on what to include in the syllabus and how they structure and teach their classes. Researchers could also collect participant syllabi, observe how participant teachers actually teach, or even how they organize their classrooms to make the learning environment both interesting and effective. Based on their findings, researchers could develop training materials and experiences for new math teachers and add to the existing pool of knowledge about math instruction.

The CDM interview technique in particular can be helpful in studying educators that are working in challenging environments. This interviewing technique can be applied to work with educators that engage in experiential teaching such as service learning projects or study abroad trips. For example, when faculty members take students on study abroad trips, they need to make decisions and solve problems in highly unstructured and usually unfamiliar environments. Host cultures might have cultural rules, values, and behaviors that are very different from the home culture. Faculty might deal with unexpected cross-cultural situations where students resist accepting unfamiliar cultural values of a host culture, student's health emergencies or inappropriate behavior, and many others unexpected challenges associated with teaching abroad. By using the CDM interviewing technique, the researcher can identify cognitive habits and mental models that these faculty members have developed over time to make decisions, solve problems, and help students make sense in unfamiliar environments. By learning about these cognitive processes and models, researchers will be able to add to the existing pool of knowledge on experiential teaching, especially in a study abroad context.

Second, CTA methods can help improve practices in education by developing training experiences for new educators. Training materials would be based on the specific findings that result from learning about mental models of expert teachers, how they make decisions in designing learning activities for their students, how they detect that students are confused about the material, or how they re-plan their syllabi to make their teaching more effective. According to Crandall et al. (2006), CTA can support future instruction by identifying cognitive training requirements, developing materials for scenarios, providing valuable feedback to trainees, and improving on-the-job training. CTA can help identify the kinds of mental models expert teachers have developed that need to be transferred to novice teachers. Effective training scenarios, simulations, and games can be developed by using the materials gathered during CDM interviews. CTA can help provide feedback to strengthen mental models and assessment about the effectiveness of training. One strategy can be for the instructor to use CDM probes to peek into trainees' minds to see what they understand and where they encounter difficulties. Lastly, it can improve on-the-job training by letting expert teachers unpack what is in their minds and share their mental models and perceptual discriminations with their co-workers.

There have been many studies that revealed the effectiveness of CTA-based workshops. For example, Klein (2004) developed trainings to improve the decision making of business executives. The executives really appreciated that CTA-based scenarios were based on their own corporate history, unique context, and not on generic business games not relative to challenges they have been facing in their own company. Crandall and Calderwood (1989) developed training materials based on CDM interviews to train nursing students in recognizing the subtle cues and patterns of newborns infected by sepsis, a potentially fatal whole-body inflammation. These students learned the cues and patterns and maintained significant recall two weeks after the training sessions.

Third, data gathered from experts through CTA methods can be useful for supporting effective teaching practices, which could impact certain policy debates in the area of effective teaching. The argument behind using CTA is that this type of research is not based in short-term observations or one-time interviews of best practices of educators. Instead, CTA is focused on learning about how teachers developed those practices, what they were thinking, and what mental processes they engaged in when dealing with challenging situations in teaching. The level of observation and in-depth questioning techniques results in a greater awareness of the cognitive decision making process which means there is a greater chance of understanding cognitive processes of an effective teacher and development of better preparation programs for new teachers. More evidence that is collected from CTA studies about its effectiveness and new developments in the fields of cognitive psychology and neuroscience can lead to changes in education policy and development of new education practices. For instance, studies using CTA could help inform how the curriculums for K-12 and higher education are developed; teaching and learning experiences can become more grounded in what is known about brain processes and functions; and future training programs and curriculum can be developed based on CTA-elicited knowledge on most effective mental models, processes, and functions shared by expert teachers. 


\section{Strengths And Limitations}

CTA studies are very helpful in eliciting knowledge and learning about cognitive elements that experts use to solve problems, make decisions, make sense of a challenging situation and to take action to complete a complex task. Another important benefit of using CTA studies is to help experts recognize mental patterns that they have developed in their journey of becoming an expert. As Hoffman (1996) pointed out there is an interesting paradox - as experts learn more, they lose awareness of what they know as well as their ability to describe or talk about it to others. That is why CTA researchers can assist experts in reflecting on what they know and how they know it; to be able to record, preserve, and transfer the most important elements in their knowledge and mental processes to train others.

Besides these important strengths, CTA methodology has several limitations. First, it is necessary to recognize that it is still under development. There is a dire need for more models and theories developed to explain how cognition works and how it can be studied. Second, many CTA methods, especially the CDM interview technique, rely on verbal reports that might not directly represent cognition. Memory recollection might also have flaws. Third, there might be a challenge in identifying "true experts" in a field, especially in the new fields, like teaching with new technology, online teaching, teaching through online games, etc. Lastly, when conducting a CDM study, the researcher needs to be trained in conducting an in-depth interview, know how to recognize mental cues, and where to expand and redirect the participant. Otherwise, the data that will be collected might not be sufficient for research purposes. The researcher also needs to have enough knowledge about mental functions and processes as well as the experience to be able to recognize them in the data collection and analysis phases.

All these limitations can be approached in a variety of ways. More models and theories will be developed through the advances in the fields of cognitive psychology and neuroscience and our understanding of how to understand and capture them will expand. To address CTA's reliance on verbal reports several techniques can be used. According to Gazarian (2013), CDM researchers are not asking the participants directly "why" certain actions have taken place. On the contrary, they are asked about specific cues, goals, and expectancies. This creates clearer representations of what actually happened during the incident. Thus, researchers need to be trained to identify such cues and to be able to recognize them while conducting interviews and analyzing the data. As for the issue of possible memory loss during recollection phase, CDM researchers explore non-routine incidents because these incidents provide more vivid recollections rather than routine procedures. That is why researchers need to encourage participants to talk about how they felt, what they smelled, touched, and experienced during the particular incident by reflecting on a variety of senses rather than on just thinking about what they generally do in solving problems and making decisions. Also, triangulation of methods and results will lead to a clearer understanding of mental functions and processes involved in choosing actions in a particular incident.

More studies that are conducted using CTA methodology can assist researchers in learning what to look for when identifying "true experts" in the new fields and in developing training materials based on effective practices. As CTA research expands there may be the need to develop collaborative training centers working across multiple disciplines and engaging with cognitive psychology and neuroscience that help researchers sharpen their skills in conducting a CTA study, recognizing cognitive functions and processes, analyzing the data, and developing effective trainings based on research findings.

\section{Conclusion}

CTA is not the sole methodology to study human cognition but just one of the tools that can be useful to shed light on how our social and cultural realities are constructed through cognitive processes and functions. CTA is a fascinating methodology that has an immense potential for the field of education. By utilizing this methodology, researchers will be able to learn more about how skillful teachers develop their pedagogical skills, make decisions about what to include in syllabi, and make sense of challenging pedagogical situations. Based on the knowledge elicited by utilizing CTA methods, effective trainings can be developed for future teachers to sharpen their teaching skills that in turn can create more effective learning experiences for their students. CTA has clear limitations and is not the only method that can be used to better understand how expert teachers are successful and effective educators. However, it does offer another lens by which to explore what makes effective teaching in terms of the cognitive processes that expert teachers employ while also offering a means to develop training practices that can benefit both teachers and their students.

\section{References}

[1] Campbell, J., Tirapelle, L., Yates, K., Clark, R., Inaba, K., Green, D., Plurad, D., Lam, L., Tang, A., Cestero, R., \& Sullivan, M. (2011). The effectiveness of a cognitive task analysis informed curriculum to increase self-efficacy and improve performance for an open cricothyrotomy. Journal of Surgical Education, 68(5), 403-407. 
[2] Chi, M.T.H. (2006). Two approaches to the study of experts' characteristics. In K.A. Ericsson, N. Charness, P. Feltovich, \& R. Hoffman (Eds.), Cambridge Handbook of Expertise and Expert Performance (pp. 121-30). Cambridge University Press.

[3] Clark, R.E. \& Este, F. (1996). Cognitive Task Analysis. International Journal of Educational Research, 25(5), $403-417$.

[4] Crandall, B. \& Calderwood, R. (1989). Clinical assessment skills of experienced neonatal intensive care nurses. Fairborn, OH: Klein Associates.

[5] Crandall, B., Klein, G., \& Hoffman, R. R. (2006). Working minds: A practitioner's guide to Cognitive Task Analysis. Cambridge, MA: The MIT Press.

[6] Creswell, J. (2002). Educational research: Planning, conducting, and evaluating quantitative and qualitative research. Saddle River, NJ: Prentice Hall.

[7] Creswell, J.W. (2007). Qualitative inquiry and research design: Choosing among five approaches (2nd ed.). Thousand Oaks, CA: Sage.

[8] Diwadkar, G.B., Hunter, C.A., and Jelovsek, J.E. (2012) Critical decision method: Eliciting principles of teaching and learning vaginal hysterectomy. Journal of Reproductive Medicine, 57(6), 463-469.

[9] Gazarian, P. K. (2013). Use of the Critical Decision Method in nursing research: An integrative review. Advances in Nursing Science, 36(2), 106-117.

[10] Guba, E. G., \& Lincoln, Y. S. (1998). Competing paradigms in qualitative research. In N. K. Denzin \& Y. S. Lincoln (Eds.), The landscape of qualitative research: Theories and issues. Sage: London.

[11] Hoffman, R. R. (1996). How can expertise be defined? Implications of research from cognitive psychology. In R. Williams, W. Faulkner, \& J. Fleck (Eds.). Exploring expertise (pp. 81-100). New York: Macmillan.

[12] Hoffman, R. R., Crandall, B. W., \& Shadbolt, N. R. (1998). Use of the critical decision method to elicit expert knowledge: A case study in the methodology of cognitive task analysis. Human Factors, 40(2), 254-276.

[13] Hoffman, R., G. Trafton, \& Roebber, P. (2006). Minding the weather: How expert forecasters reason. Cambridge, MA: MIT Press.

[14] Hruby, G. G., \& Roegiers, A. (2012). Cognitive constructivism. In C. A. Chappell (Ed.), Encyclopedia of Applied Linguistics. Oxford, UK: Wiley-Blackwell.

[15] Klein, G. (2004). The power of intuition. New York: Doubleday.

[16] Klein, G., \& Militello, L. (2004). The knowledge audit as a method for cognitive task analysis. In H. Montgomery, R. Lipshitz, \& B. Brehmer (Eds.), How professionals make decisions (pp. 335-342). Mahwah, NJ: Lawrence Erlbaum Associates.

[17] Klein, G., Pliske, R. M., Crandall, B., \& Woods, D. (2005). Problem detection. Cognition, Technology, and Work, 7(1), 14-28.

[18] Lincoln, Y. S. \& Guba, E. G. (1985). Naturalistic inquiry. Beverly Hills, CA: Sage.

[19] Shenton, A. K. (2004). Strategies for ensuring trustworthiness in qualitative research projects. Education for Information, 22(2), 6375.

[20] Sullivan, M. E., Ortega, A., Wasserberg, N., Kaufman, H., Nyquist, J., \& Clark, R. E. (2008). Assessing the teaching of procedural skills: Can Cognitive Task analysis add to our traditional teaching methods? American Journal of Surgery, 195(1), $20-3$.

[21] Weick, K. E. (1995). Sensemaking in organizations. Thousand Oaks, CA: Sage.

[22] Yates, K. A., Sullivan, M. \& Clark, R.E. (2012). Integrated studies in the use of cognitive task analysis to capture surgical expertise for central venous catheter placement and open cricothyrotomy. The American Journal of Surgery, 203, 76-80. 